\title{
Effects of informative stimuli with multiple delays of reinforcement*
}

\author{
STEPHEN B. KENDALL \\ University of Western Ontario, London 72, Ont., Canada
}

Three pigeons were trained in a procedure in which pecking a dark key produced one of two stimuli (red or green lights). Equal delays or different delays to food presentation were programmed in these stimuli. In the first phase of the experiment, the delay in green was kept constant at $15 \mathrm{sec}$, while the delay in red was $15,30,45$, and 55 sec, in that sequence. This manipulation had no apparent effect on the response rate to the dark key. In the second phase, the delay in green was $15 \mathrm{sec}$ and the delay in red was 15,120 , and $15 \mathrm{sec}$, in that sequence. Increasing the delay in red to $120 \mathrm{sec}$ produced an increased response rate in the presence of the dark key, and decreasing it back to 15 sec produced a decrease. In the final (control) condition, the delays were again 15 or 120 sec, but these delays were not reliably signaled by the red or green lights. The response rate did not increase above the level for the equal 15-sec delay condition.

Wilton \& Clements (1971, Experiment II) have reported that pigeons will peck faster to produce stimuli in which they are reinforced $50 \%$ of the time than they will to produce stimuli in which they are reinforced $100 \%$ of the time. In their experiment, the stimuli in one of two $50 \%$ reinforcement conditions predicted the outcome of the trial, either reinforcement or a brief time-out. In the other $50 \%$ condition, the stimuli did not predict reinforcement or time-out. In all three conditions, the trial outcome was delayed from the onset of the stimulus. Response rates were low in the $100 \%$ and $50 \%$ noninformative condition and high in the $50 \%$ informative.

Wilton and Clements referred to this procedure as an observing response procedure, although in most observing response experiments the observing response need not be emitted in order that reinforcement be obtained, as in the Wilton and Clements experiment. The Wilton and Clements procedure is something of a mix between observing response procedure and a delayed reinforcement or chain schedule procedure.

It is known that differential delays of reinforcement will support observing responses when observing responses are not a requirement for the production of reinforcement (Bower, McLean, \& Meacham, 1966). The present experiment investigated response rate in a situation in which there were two delays of reinforcement. A reasonable

*This research was supported by Grant APA-258 from the National Research Council of Canada. I am indebted to $\mathrm{Mr}$. William Mills for help in collecting the data. Reprints may be obtained from the author Department of Psychology, University of Western Ontario, London 72 , Ont., Canada. hypothesis from previous data is that the response rate will be higher when one delay is long and one short than when both are short if each delay is accompanied by a distinctive stimulus.

\section{SUBJECTS}

The Ss were three male White King pigeons. All three were experimentally naive.

\section{APPARATUS}

The apparatus was a Lehigh Valley Electronics pigeon chamber. It contained two keys, but only the left-hand key was used in this experiment. Programming was done with electromechanical equipment, and data were taken on counters and elapsed time meters.

\section{PROCEDURE}

The pigeons were initially trained by successive approximation to peck at the response key when it was dark. Initially, they were given 3 sec access to mixed grain as the reinforcer. During the feeder presentation, the houselight went out. Following this training, they were given training with delayed reinforcement. A single keypeck produced one of two lights (red or green) which transilluminated the response key. These colors appeared in an unpredictable sequence, each occurring on half of the trials. The delay from the keypeck to reinforcement was gradually increased over several sessions to 15 sec. Reinforcement occurred regardless of which color appeared during the delay interval. Any keypeck occurring during the final $2 \mathrm{sec}$ of a delay reset a clock and caused reinforcement to be delayed for a further 2 sec. Immediately following reinforcement, the key was dark and the bird could peck immediately and initiate another delay. The time from the onset of the dark key to reinforcement is called a trial. Thirty trials were given per session. When the delay had been lengthened to $15 \mathrm{sec}$, the number of keypecks required to produce a stimulus was increased to five (FR 5). The birds were then allowed to stabilize with the delay set at $15 \mathrm{sec}$ regardless of the stimulus and the fixed-ratio set at FR 5 .

When the rate of responding had stabilized in the above condition, the delay in the red light was increased, but the delay in green remained at $15 \mathrm{sec}$. The delay in red was first increased to $30 \mathrm{sec}$, then $45 \mathrm{sec}$, and finally $55 \mathrm{sec}$. During this more or less exploratory phase, the birds were left in one delay condition for only about 10 sessions. If some trend did not develop in the rate of responding, the delay was further increased. After being exposed to the 55 -sec delay, the birds were returned to equal delays of $15 \mathrm{sec}$ in both red and green. They were trained in this condition for 17 sessions. Then the delay in red was again altered to $120 \mathrm{sec}$, and the birds were trained in this condition for 26 sessions and then returned to equal delays of $15 \mathrm{sec}$ for 15 sessions. In the final (control) phase of the experiment, the delays were again set at 15 and $120 \mathrm{sec}$, but the stimuli were not consistently associated with a given delay. Thus, either a $15^{-}$or 120-sec delay might occur in either red or green. They were trained in this condition for 15 sessions.

The condition where both delays were $15 \mathrm{sec}$ will be called the equal delay condition. Multiple delay will refer to the conditions where there were unequal delays both reliably signaled. The condition where there are two different delays not reliably signaled will be called the mixed delay condition.

\section{RESULTS}

The data from the initial portion of the experiment, where the delay in red was changed from 15 to 30,45 , and finally to $55 \mathrm{sec}$, are not presented, since these changes in delay led to no systematic changes in the rate of responding. Figure 1 shows the rate of responding plotted across sessions for each bird for the final four stages of the experiment. In the first panel, data from the second exposure to the equal delay condition are plotted. In the second panel, the response rate from the $15 \mathrm{sec}$ in green, $120 \mathrm{sec}$ in red multiple delay condition are shown. The third panel shows the return to equal delay, and the final panel shows the rates from the mixed delay condition.

For all birds, the response rate increased in the multiple delay condition above the equal delay condition. The response rate decreased when they were returned to the equal delay, but showed no increase in the mixed delay. The change in going from 


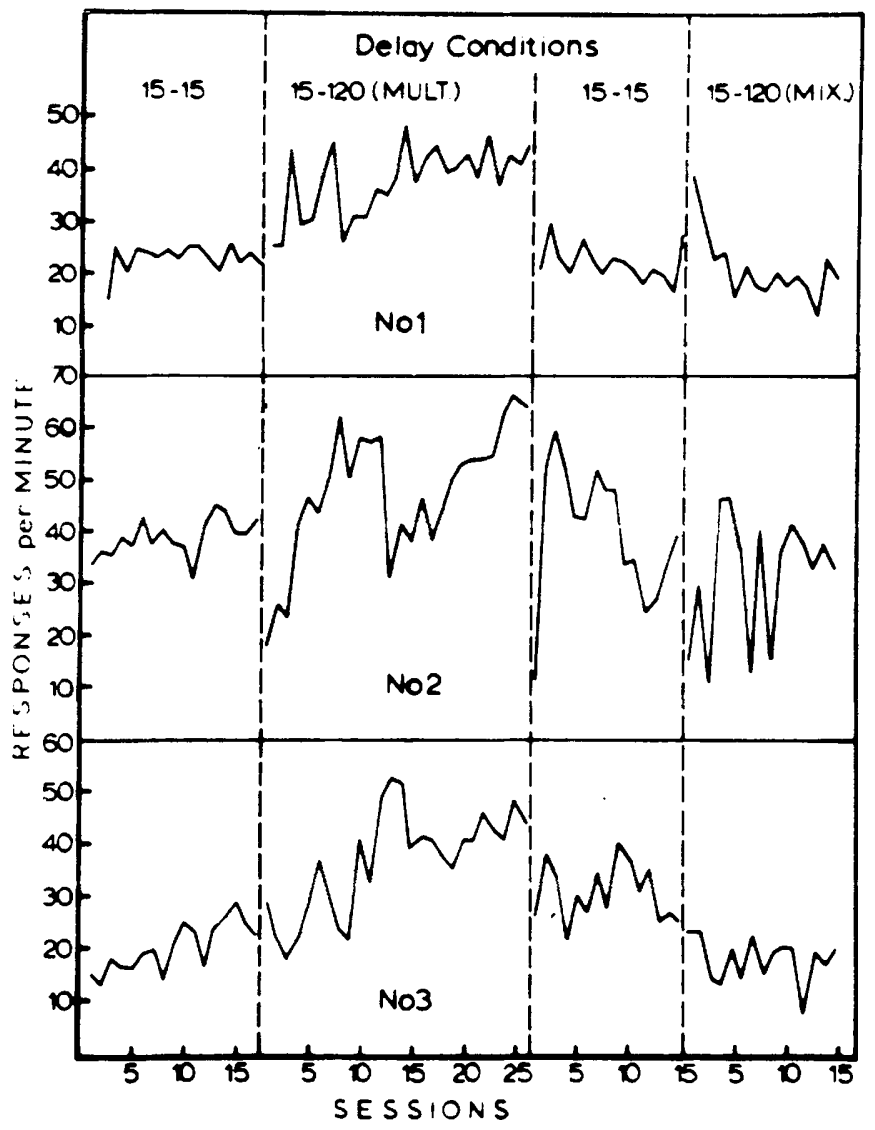

Fig. 1. Response rates across sessions in the dark key for each bird in four conditions. The first panel shows response rates in the equal delay condition. The second panel shows response rates in the multiple delay condition with the delay in red at $120 \mathrm{sec}$. The third panel shows the return to the equal delay condition, and the last panel shows rates in the mixed delay condition with 15 . and 120 -sec delays.

equal delays to multiple delays was fairly gradual, but the change in going from multiple delay to equal delay was rapid, especially for Birds 1 and 3 . The data from Bird 2 display considerable variability in the last three panels, often showing unpredictable increases or decreases.

Responses in the presence of the delay stimulus were almost nonexistent, perhaps due to the postponement contingency in the last $2 \mathrm{sec}$ of the trial. No data on these responses are reported here.

$$
\text { DISCUSSION }
$$

The results substantiated the hypothesis that increasing one of the delays would produce an increase in response rate if the delays were differentially signaled. Delays of up to about $1 \mathrm{~min}$ in red were ineffective in producing this effect, but a delay of $2 \mathrm{~min}$ in red did. These findings extend the generality of the data of Wilton \& Clements (1971, Experiment II), who found that removing reinforcement from one of the stimuli produced a higher rate with

These results show that conditions which are known to support observing responses in situations where the observing response is not required for reinforcement also will produce a equal delays. higher response rate in a modified chain schedule or delay of reinforcement procedure. The difference between a simple chain schedule and the present case is that, in the simple chain schedule, only one stimulus is presented as a consequence of responding in the initial component (the dark key, in the present experiment). Two stimuli signaling different outcomes or delays, however, were used in the present experiment and the one by Wilton and Clements.

The findings violate the principle that the rate of responding in the initial link of a two-link chain schedule is an increasing function of the rate of reinforcement in the final link (Kelleher, 1966). The crucial difference between the simple chain procedure and the present procedure is the use of stimuli that may be characterized as informative in the present case. It appears that the use of informative stimuli to signal different events or delays has one of two effects. It might add to the value of the delay stimuli, even though the overall rate of reinforcement is lower. A second hypothesis is that there is some motivational effect from anticipatory frustration. This mechanism has been hypothesized to account for the partial reinforcement acquisition effect (Amsel, 1967; Spence, 1960, Chap. 6). Which of these alternatives is correct cannot be decided by currently available data.

\section{REFERENCES}

AMSEL, A. Partial reinforcement effects on vigor and persistence: Advances in frustration theory derived from a variety of within-subject experiments. In $\mathrm{K}$. W. Spence and J. T. Spence (Eds.), The psychology of learning and motivation. Vol. 1. New York: Academic Press, 1967. Pp. 1-65.

BOWER, G. MCLEAN, L., \& MEACHAM $J$. Value of knowing when reinforcement is due. Journal of Comparative \& Physiological Psychology, 1966, 62, 184-192.

KELLEHER, R, T. Chaining and conditioned reinforcement. In $\mathrm{W}$. $\mathrm{K}$. Honig (Ed.), Operant behavior: A reas of research and application. New York: A p pleton-Century-Crofts, 1966 . Pp. 160-212.

SPENCE, $\mathrm{K}$. W. Behavior theory and learning. Englewood Cliffs, N.J: Prentice-Hall, 1960.

WILTON, R. N., \& CLEMENTS, R. O Observing responses and informative stimuli. Journal of the Experimental Analysis of Behavior, 1971, 15, 199-204. 